\title{
Pichia pastoris - recombinant enzyme producent for environment treatment - review
}

\author{
Tamara Kyzeková, Vladimír Krasňan, Martin Rebroš \\ Insitute of Biotechnology, Slovak University of Technology, \\ Radlinského 9, 81237 Bratislava, Slovakia \\ martin.rebros@stuba.sk
}

\begin{abstract}
Since environmental pollution is increasing, scientists try to find a sustainable way for its clean up and for environment protection. Due to increasing knowledge of genetics and recombinant technologies, recombinant enzymes have been increasingly applied for these purposes. This article deals with the possibilities of environmental treatment with different types of enzymes produced by $P$. pastoris. Environment is polluted mostly with pesticides, wastewaters, phenol compounds, plastics, toxic compounds, wastes from medical treatment, etc. All these compounds have to be eliminated considering the deteriorating biodiversity, human health, and condition of plants. Enzymes are an environmentally friendly way of such treatment.
\end{abstract}

Keywords: Pichia pastoris, recombinant enzymes, environment, pollution

\section{Introduction}

In the last century, a massive expansion of oil industry and different industries have negatively affected our environment. The situation got serious a long time ago and that is why scientists already devised some ways to stop damaging and even partially restore environment. First significant effort was the concept of chemical catalysis which dealt with catalytical reduction of contaminants derived from petroleum. The idea started in the 1960 s and was in its heyday in the 1990s due to widespread application of chemical catalysis in industry (Alcade et al., 2006). Nowadays, longterm use of chemical catalysis is questioned mostly because of its health risks, and waste and toxic compounds production. Even though chemical catalysis has advantages in reducing chemicals footprint, a "cleaner technique", biocatalysis, had to be introduced. Its concept was introduced in the 1990 s and it is still interesting as an environmentally friendly technique. Basically, it is an application of microorganisms, or their enzymes, in the production of renewable and clean products replacing chemical catalysts mainly due to their negative environmental impact or energy and raw material requirements. Biocatalysis requires mild reaction conditions and it offers high activity products and chemo-, regio- and stereoselectivity (Sheldon \& van Rantwijk, 2004). The same enzymes and microorganisms can also be used for the remediation of toxic wastes. Biocatalysis is very closely connected with recombinant techniques (Alcade et al., 2006). Combined with remediation efforts, microorganisms producing recombinant enzymes for environment remediation. Also, bioindustry wastes are studied as carbon source for some microorganisms. Attention, especially these days, is focused on crude glycerol.

\section{Pichia pastoris}

One of the most widely used microorganism in recombinant technologies is Pichia pastoris. This methylotrophic yeast belongs to the family of Saccharomycetaceae (Satyanarayana \& Kunze, 2009) and its genome was sequenced in 2009, which opened the door to further research (Schutter et al., 2009). Previously, in the 1970 s, $P$. pastoris was used as "single cell protein" (SCP) producer for animal feeding. At that time, there was an effort to produce SCP from cheap carbon sources, e.g. methanol. P. pastoris later became the most cited methylotrophic yeast, but due to oil crisis, this interest decreased. Ten years later, the company which started to use P. pastoris for SCP - Philips Petroleum - together with the Salk Institute of Biotechnology prepared a strain for heterologous expression for academic and industrial purposes (Cos et al., 2006). Since the production of a functional heterologous protein expression is closely related to the metabolism of the production microorganism, $P$. pastoris offers several advantages in this respect. It is suitable for the expression of milligrams up to grams of protein per liter of fermentation broth - for basic laboratory research but also for industrial production. The advantages include its easy production in fermenters, where it is possible to regulate parameters affecting protein productivity, such as $\mathrm{pH}$, aeration, the amount of carbon source supplied and induction of protein production. Compared to other producers, $P$. pastoris does not need complex growth media and the culture conditions are easily ensured. Yeasts are easily manipulated on the genetic level and their protein synthesis is similar to 
that of higher organisms. Therefore, some proteins that cannot be efficiently expressed in bacteria, Saccharomyces cerevisiae or baculoviruses are often produced in functionally active forms in $P$. pastoris. These yeasts are beneficial for several reasons: easy genetic manipulation, functional complementation cloning, high-frequency DNA transformation, high intra- and extracellular protein production, and post-translational modifications of proteins. The yeast's post-translation modifications include disulfide bridge formation, glycosylation, and phosphorylation. During the cultivation, high cell densities are achieved using minimal media, which means production of proteins can reach high yields. Also, vectors with recombinant genes are integrated into the yeast chromosome which makes them genetically stable even in continuous and large-scale fermentation processes. At the same time, recombinant $P$. pastoris produces low levels of native proteins facilitating the purification of recombinant proteins. Powerful and available genetic techniques, together with the overall economics of the process, make $P$. pastoris a suitable expression system for the production of homologous proteins (Macauley-Patrick et al., 2005).

Cultivation of $P$. pastoris consists of two steps. The first is the growth of $P$. pastoris on glycerol to reach high cell density. Then, after glycerol depletion, methanol is added to the medium and protein production begins (Markošová et al., 2015).

The beginning of the methanol pathway (Fig. 1) in $P$. pastoris is in special organelles - peroxisomes and continues in cytoplasm. First step, where formaldehyde and hydrogen peroxide are formed, is catalyzed by alcoholoxidase (AOX). For methanol utilization, dihydroxyacetone synthase is necessary for formaldehyde assimilation in peroxisomes. A part of formaldehyde leaves the peroxisomes and is further oxidized by cytoplasmic dehydrogenases to formate and carbon dioxide. These reactions are an important source of energy for the cell growth (Cereghino \& Cregg, 2000). Genetically modified $P$. pastoris has, under AOX promoter control, located the gene encoding the homologous protein of interest. This promoter is induced only by methanol, which means methanol is the carbon source as well as the inductor. Since formaldehyde is formed during its utilization, methanol has to be added carefully due to its toxic effect (Markošová et al., 2015).

As mentioned above, $P$. pastoris initial substrate is usually glycerol, which is mainly used as pure compound. However, several publications show that $P$. pastoris is also able to grow on industrial crude glycerol (Anastácio et al., 2014). It is a by-product of biodiesel production and in the last decades started to be an environmental burden (Bartocci et al., 2018). The possibility of utilizing crude glycerol is only one way in which $P$. pastoris can participate in the reduction of environmental pollution. It has also great potential in the production of proteins, which can help the environment directly. Genetic engineering tools and commercial P. pastoris strains availability are also important advantages of this yeast application in research and industry (Fisher \& Glieder, 2019).

\section{Recombinant products of Pichia pastoris and their use in the environment}

\section{Antimicrobial peptides}

Currently, the massive use of pesticides in the agro-sector causes significant pollution. Pesticides have been used worldwide and for many years to prevent pathogen diseases of plants. On the other hand, pesticide residues accumulate in soil and from there they can reach drinking water supplies. In the 1990s, a study by U.S. Geological Survey

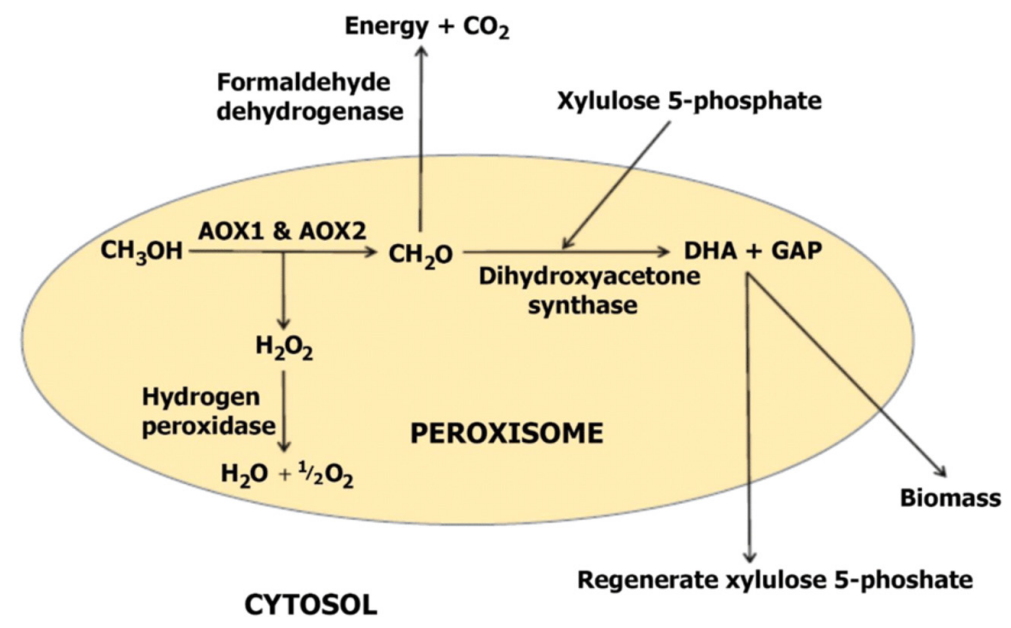

Fig. 1. Methanol pathway of P. pastoris (Ali et al., 2020). 
(USGS) stated that $90 \%$ of fish samples and water from all streams were contaminated by one or several pesticides. According to USGS, pesticides from every major chemical class were found in ground water and its pollution is a worldwide problem (Aktar et al., 2009). From water, pesticides can easily enter any organism. There is evidence that they cause cancer, respiratory problems, neurologic deficiency, birth defects, miscarriages or dermatologic difficulties (Bassil et al., 2007) (McCauley et al., 2006). Moreover, biodiversity is damaged since many animals are endangered by them (Mahmood et al., 2006). Pathogens have become resistant to pesticides, and new and more environmentally safe agents are needed.

One of the antimicrobial peptides is pexiganan, which has lethal effect on many types of undesirable microorganisms. It attacks the bacterial membrane resulting in pores on their surface and thus causing their death (Lazarev \& Govorun, 2010). This peptide is recombinantly produced by $P$. pastoris because it has low sensitivity to almost no antimicrobial effect in eukaryotic cells. Thanks to that, large quantities can be produced without damaging the host microorganism. For example, production of recombinant peptide via $E$. coli reached $30 \mathrm{mg} / \mathrm{L}$ (Sun et al., 2018) while via P. pastoris it was $52 \mathrm{mg} / \mathrm{L}$. Furthermore, to avoid E. coli inhibition, inactivation sequence is added to the peptide gene which has to be cleaved using thermal, enzymatic or chemical methods leading to higher production costs and partial loss of produced peptide. Recombinant peptide produced in $P$. pastoris was tested on eight plant pathogens causing significant economic losses in agriculture industry and on two human pathogens (Tab. 1). Pexiganan showed 500 times stronger antimicrobial activity than copper oxychlo- ride which is a common chemical pesticide against plant pathogens. Peptide has high long-term stability and temperature resistance. According to calculations, production of $52 \mathrm{mg}$ of recombinant peptide costs about $10 \$$, while synthetic production of crude pexiganan is 20-30 times more expensive and in case of $98 \%$ purity, it is even 120 times more expensive (Neshani et al., 2019), (www.entonbio. com; www.synpeptide.com).

Pathogens elimination can also be done using killer toxin produced by the yeast Tetrapisispora phafi. Killer toxin, known as Kptk, has $\beta-1,3$ glucanase and killer activity which induces ultrastructural modifications to the cell wall of the yeast of genera Kloeckera/Hanseniaspora and Zygosaccharomyces causing spoilage of grapes and losses in wine and sweet beverage production. Recombinant killer toxin was produced by $P$. pastoris and reached final concentration of $23 \mathrm{mg} / \mathrm{L}$ which is significantly more than the amount produced by native Tetrapisispora phaffi . Moreover, compared to native Kpkt, recombinant Kpkt shows a wider spectrum of activities, e.g. toxic effect on Dekkera bruxellensis, spoilage yeast in wine making and biofuel industry (Chessa et al., 2017).

\section{Pesticides}

Enzymes are also applied for pesticides monitoring and their degradation. One of them is organophosphorus hydrolase from Pseudomonas pseudoalcaligenes (Shen et al., 2016) which can be used for biodegradation of residues from organophosphorus pesticides or their detection (Mulchandani et al., 1998). These pesticides are synthetic esters, amides, or thiol derivates of phosphonic, phosphoric or phosphonothioic acid. They are widely used in agriculture and domestic cultivation. Organophosphorus pesticides were

Tab. 1. Minimum inhibitory concentration of recombinant pexiganan and cooper oxychloride needed for lethal effect on pathogen (Neshani et al., 2019).

\begin{tabular}{|c|c|c|c|}
\hline & & \multicolumn{2}{|c|}{ Minimum inhibitory concentration $(\propto \mathrm{g} / \mathrm{ml})$} \\
\hline & & $\begin{array}{c}\text { Pexiganan-based } \\
\text { biopesticide solution }\end{array}$ & Cooper oxychloride $35 \% \mathrm{WP}$ \\
\hline \multirow{8}{*}{$\begin{array}{l}\text { Plant } \\
\text { pathogens }\end{array}$} & Pseudomonas syringae pv. syringae & 0.81 & 625 \\
\hline & Ralstonia solanacearum & 0.4 & 1250 \\
\hline & Pantoea stewartiii & 0.4 & 312.5 \\
\hline & Xanthomonas arboricola pv. pruni & 0.81 & 625 \\
\hline & Erwinia amylovora & 0.4 & 2500 \\
\hline & Pectobacterium carotovorum & 0.4 & 625 \\
\hline & Agrobacterium tumefaciens & 0.4 & 1250 \\
\hline & Brenneria nigrifluens & 0.4 & 312.5 \\
\hline Human & Staphylococcus aureus ATCC 25923 & 8 & - \\
\hline pathogens & Escherichia coli ATCC 25922 & 16 & - \\
\hline
\end{tabular}


detected in soil and drinking water long after their application and they belong to the most toxic pesticides causing long-term damage to human health since they inhibit the enzyme acetylcholinesterase which is essential for the function of central nervous system (Songa \& Okonkwo, 2016). Decontamination methods for these pesticides are often toxic, corrosive, allergic and not environmentally friendly and thus it is essential to hydrolyze them, preferably with enzymes (Farnoosh \& Latifi, 2014). Organophosphorus hydrolase was produced on $\mathrm{pu}-$ rified glycerol with later methanol induction by $P$. pastoris. Recombinant organophosphorus hydrolase had good biodegradation properties and expression reached high level $(7.8 \mathrm{~g} / \mathrm{L}$ of protein); this production can provide an effective way of dealing with organophosphorus pesticides. Activity of this enzyme was measured by hydrolysis of substrate methyl parathion, a popular organophosphorus pesticide widely used for crop protection, its activity reached $21.6 \mu \mathrm{mol} / \mathrm{h} / \mathrm{mg}$ of wet weight (Shen et al., 2016). To compare, organophosphorus hydrolase produced in Moraxella sp. Hydrolysing reached the activity of only $0.6 \mu \mathrm{mol} / \mathrm{h} / \mathrm{mg}$ of dry weight using the same substrate (Shimazu et al., 2001).

Wastewater, phenol compounds and lignin treatment Historically, the most well-known enzymes used for bioremediation of wastewater and soils are wood-destroying fungal enzymes involved in lignin degradation (laccase, lignin peroxidase, manganese peroxidase). Water and soils are widely polluted with chemical compounds like phenol, aromatic amines, synthetic dyes, antibiotics, hydrocarbons, chlorine etc., which have negative effect on the biodiversity or plant and human health. Since industry is very developed and these pollutants are still used, there is no other option than to eliminate them. The use of oxidative enzymes for their biodegradation is environmentally friendly, low cost and more effective compared to physical and chemical methods which have many disadvantages such as hazardous by-products or limited degradation activity (Alcade et al., 2006). Besides biodegradation, the mentioned enzymes can also be used in other industrial sectors. First and the most studied enzyme is laccase, which can be found in bacteria, fungi, higher plants and even insects. Laccase finds its application in the following industries: food, paper, pulp, textile, cosmetics, and it is used for bioremediation, removal of endocrine disruptors and biodegradation of phenolic pollutants. Laccases are also able to oxidize non-phenolic lignin-related compounds. An important environment application of laccase is decolorization of dyes (Shraddha et al., 2011). More than 100,000 dyes are commercially available, most of which are very difficult to eliminate from water due to their complicated structure and synthetic origin. They are specially designed to resist fading after exposure to light, water and oxidizing agents. Due to their high stability, wastewater treatment techniques to decompose them include electrochemical destruction, membrane filtration, electroflotation, ozonation, ion exchange or adsorption (Nigam et al., 2000). The use of enzymes is a more simple, clean, and effective technique leaving less waste. One of the examples of enzymatic treatment is detoxification and reduction of color and aromatic compounds of black liquor - wastewater from pulp production. Detoxification was performed with Tramates versicolor producing laccase. This microorganism was also used for complete decolorization of Amaranth, Congo Red, Reactive Black 5, Tropaeolin O, and Reactive Blue 15 colors (Ramsay \& Nguyen, 2002). In bioremediation, laccase also achieves excellent results; laccase from $T$. villosa removed $100 \%$ of 2,4-dichlorophenol from soil (Ahn et al., 2002). Recently laccases have been applied in nanobiotechnology, since they are able to catalyze electron transfer reactions with no additional cofactors (Shraddha et al., 2011). Laccase and other ligninolytic enzymes are produced during the secondary metabolism of fungi under nitrogen or other nutrient limited conditions when they are secreted in the medium extracellularly. Most widely known species for laccase production are Basidiomycetes and Saprotrophic fungi and the production usually proceeds via solid-state or submerged fermentation, which have some disadvantages like broth viscosity, oxygen and mass transfer problems (Moreira et al., 2003). Laccase production via solidstate and submerged fermentation does not reach the maximum yield and it is not possible to produce large volumes of highly active enzyme at affordable cost (Shraddha et al., 2011).

Although enzymes are widely used, due to the slow growth of fungi and the mentioned disadvantages, their recombinant production by Pichia is a more effective way of production (Xu et al., 2017). As an example, recombinant laccases from Pleurotus ostreatus produced by $P$. pastoris were capable of efficient removal of nitrophenols, chlorophenols and sulfonamide antibiotics (Fig. 2), dangerous agents with high toxicity and carcinogenic effect. Their residues were found mainly in wastewater. The best degradation effect was achieved in case of sulfonamide antibiotics (sulfadiazine: $98.1 \%$, sulfamethazine: $97.5 \%$ and sulfamethoxazole: $97.8 \%)$. Degradation of nitrophenols was also successful (2-nitrophenol: 59.21 \%, 3-nitrophenol: $47.91 \%$ and 4-nitrophenol: $60.24 \%)$. The worst results were obtained for chlorophenols (4-chloro- 

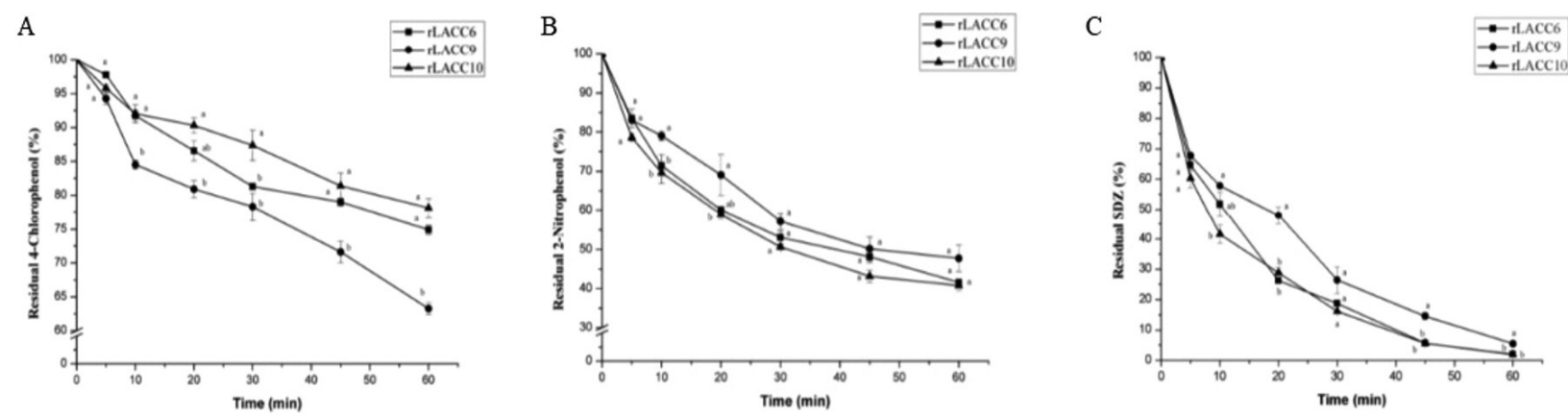

Fig. 2. Degradation of 4-chlorphenol (A), 2-nitrophenol (B) and sulfadiazine (C) by three recombinant laccases produced by $P$. pastoris (Zhou et al., 2018).

phenol: $47.9 \%$, 2,4-dichlorophenol: $28.9 \%$ and 2,6-dichlorophenol: 35.1\%) (Zhou, et al., 2018). In comparison, laccase from $T$. versicolor provided $97 \%$ degradation of 4-nitrophenol (Levil et al., 2016) and laccase from T. pubescens ensured $41.1 \%$ degradation of 2,4-dichlorphenol (Gaitan, et al., 2011). However, this result may be affected by the cooperation of multiple enzymes in fungi. Also the reaction mixture for laccase from $T$. pubescens and T.versicolor contained $15 \mathrm{mg} / \mathrm{L}$ and $139 \mathrm{mg} / \mathrm{L}$ of the pollutant while recombinant laccase showed the concentration of $100 \mathrm{mg} / \mathrm{L}$. Degradation ability of recombinant laccase was observed only for 1 hour and in case of native laccase from $T$. pubescens and T. versicolor, a 4 and 72 hour experiments were done, respectively. Based on these results, it can be concluded that recombinant laccase has better degradation ability the native one (Zhou et al., 2018).

Different types of laccase from the wood-destroying fungi $T$. trogii was also successfully expressed in $P$. pastoris (Colao et al., 2006). The recombinant enzyme exhibited similar specific activity (232 U/mg) and the same properties as the native one. Its decolorizing ability was tested on synthetic dyes including azo dyes, triarylmethane, indigo carmine and the anthraquinonic dye alizarin red S. Relative decolorization (almost $100 \%$ ) was the highest in case of blue indigo and since this is the most important dye in blue jeans manufacturing, it is an important advantage of recombinant laccase. Moreover, production of recombinant laccase achieved concentrations (129,6 mg/L) which, according to the authors, exceeds that obtained from T. trogii cultures, which also produce a number of laccase isoforms and are difficult to separate since they have similar chemico-physical properties. This does not happen in case of $P$. pastoris production (Colao et al., 2003).

Another ligninolytic enzyme is manganese peroxidase catalyzing the depolymerization of plant lignin. Manganese peroxidase is one of the most common lignin degradation enzymes and has great potential in agriculture for its ability to degrade cellulose, hemicelluloses, and lignin. It was first isolated in 1985 from the wood-destroying fungus Phanerochaete chrysosporium (Paszczyński et al., 1985). It is the most abundant lignolytic enzyme in nature. Currently, it has been isolated and characterized from several fungi and its properties are the subject of extensive research. Many studies suggest manganese peroxidase to effectively degrade azo dyes. In the field of environmental protection, it is also used for the degradation of organic and toxic substances such as polycyclic aromatic hydrocarbons, chlorophenols, industrial dyes and nitroaromatics (Xu et al., 2017). Polycyclic aromatic hydrocarbons are derived from industrial activities causing health risks due to their carcinogenic and mutagenic potential. Manganese peroxidase from Bjerkandera sp. degraded them (specifically anthracene, dibenzothiophene and pyrene) to a large extend and in a short period of time, 7 hours for anthracene, and 24 hours for dibenzothiophene and pyrene (Eibes et al., 2006). Manganese peroxidase from Pleutorus ostreatus detoxicated aflatoxin, which is a mycotoxin with carcinogenic, mutagenic, hepatogenic and immunosuppressive properties (Yehia, 2014). Enzyme from Phanerochaete chrysosporium was successful in removing tetracyclines and oxytetracyclines. The results show that manganese peroxidase degraded $72.5 \%$ of tetracyclines and 84,3\% of oxytetracyclines (Wen et al., 2010). Manganese peroxidase crude enzyme extract of Nematoloma frowardii and Stropharia rugosoannulata proved to convert several aminonitrotoluens such as 2-amino-4,6-dinitrotoluene, 4-amino-2,6-dinitrotoluene and 2,6-diamino-4-nitrotoluene (Scheibner \& Hofrichter, 1998). All mentioned application showed great potential in the removal of impurities from the environment. However, natural production of this enzyme is disadvantageous due to the slow growth of fungi, accumulation of extracellular polysaccharides, or production of compounds with similar chromatographic properties. Therefore, recom- 
binant microorganisms have been studied for its production (Xu et al., 2017).

Manganese peroxidase from Ganoderma lucidum produced by $P$. pastoris was tested for phenol and synthetic azo dyes degradation (Xu et al., 2017). It was proved that during photocatalytic degradation of azo dyes, several aromatic intermediates are produced (Fig. 3). They are harmful to the nature and human health (Tanaka et al., 2000).

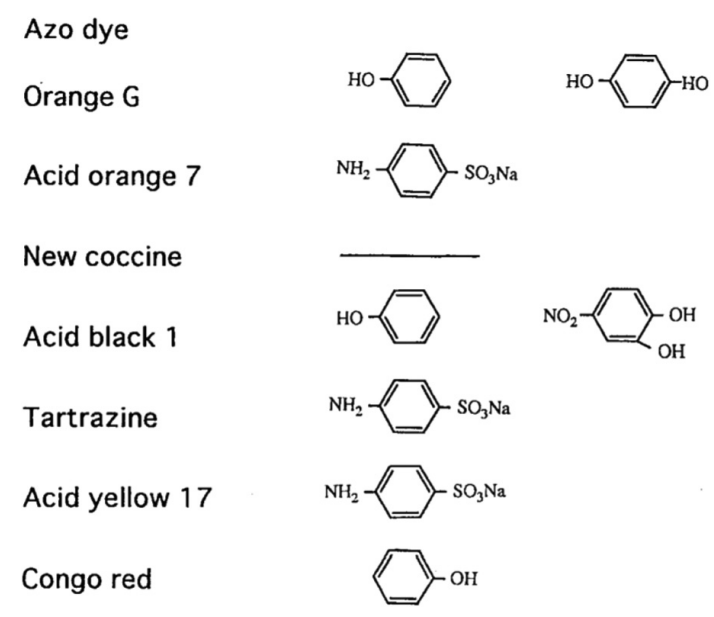

Fig. 3. Intermediates (phenolic compounds, aromatic amines) in photocatalytic degradation of azo dyes (Tanaka et al., 2000).

It is an advantage that manganese peroxidase can degrade both phenol and synthetic dyes. There are several studies confirming that manganese peroxidase decolorizes wastewaters from factories. However, expression on high level has to be considered before commercial use. In many isolates it is usually too low for industrial application but $P$. pastoris could meet these requirements. Compared with the natural host, $P$. pastoris increases expression levels by 10-, 100- or even 1000-fold. Recombinant enzyme from $P$. pastoris was produced with specific activity of 524,61 U/L and final yield of $126 \mathrm{mg} / \mathrm{L}$. Activity of manganese peroxidase was confirmed through its ability to degrade phenol which was monitored chromatographically. In case of the tested synthetic dyes, the results are easily visualized (Fig. 4). In Figure (c) are dyes before degradation and Figure (d) shows dyes after applying crude protein extract of recombinant $P$. pastoris containing manganese peroxidase. Decolorization of all dyes reached $70 \%$ (Xu et al., 2017).

Manganese peroxidase is also important in pulp and paper industry. Pulp mills discharge a wide range of chlorinated and non-chlorinated organic compounds because they use molecular chlorine for bleaching. Chlorinated compounds include chlorinated phenolic derivatives and chlorinated

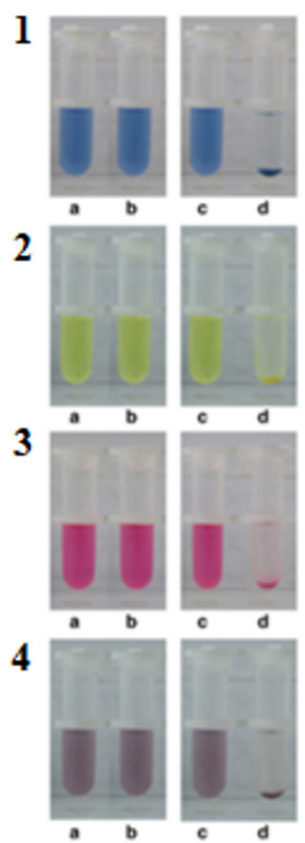

Fig. 4. Visual representation of dyes degradation: Drimaner Blue CL-BR (1), Yellow X-8GN (2), Drimaren Red K-4BI (3) a Disperse Navy Blue HGL (4). On the left side: crude protein extract of non-recombinant $P$. pastoris used as a control at the beginning (a) and the end of dye degradation (b). On the right side: (c, d) is crude protein extract of recombinant $P$. pastoris containing manganese peroxidase at the beginning (c) and the end of dye degradation (d) (Xu et al., 2017).

dioxins and furans, and they are known to accumulate in the tissue of fish (Owens et al., 1994). Public has forced pulp and paper mills to reduce chlorinebased chemicals and use more environmentally friendly bleaching techniques based on enzymes like manganese peroxidase. Results from P. pastoris manganese peroxidase fermentation showed that recombinant enzyme can degrade lignin and it is very effective when combined with alkaline extraction in delignification and brightening. Kappa number of the resulting pulp was reduced by $61 \%$, to 8.6 (ideal value should be below 6.5 (Viikari et al., 1968)) and brightness increased by 26 points (Xu et al., 2010).

Another enzyme involved in lignin degradation is lignin peroxidase, which oxidizes non-phenolic substrates. Lignin is an aromatic polymer which protects plants from microbial attacks. Lignin degradation in nature is interesting because it is an essential part of the carbon cycle and it is unusually biochemically stable (Hammel et al., 1993). Lignin as a waste is generated as a by-product from pulping or ethanol production. Due to its complex structure, it is an environmental burden and its degradation is essential (Li \& Takkellapati, 2018). 
Lignin peroxidase was expressed in various hosts. One of them was Escherichia coli. Even though the enzyme production was fast and provided high yields, it was limited by the low yield of subsequent in vitro refolding. This was necessary due to the lack of haem incorporation inside the cells and formation of inclusion bodies. Lignin peroxidase was also expressed in baculovirus with low yield of active peroxidase and high production cost. The yield in Aspergillus niger was also comparatively low. On the other hand, production of recombinant lignin peroxidase in $P$. pastoris was successful and was it proved that multicopy transformation of plasmid increases the final yield. Activity of the enzyme reached $15 \mathrm{U} / \mathrm{L}$ after a 12 hours induction (Wei \& Xianghua, 2009).

From peroxidases, horseradish peroxidase is another interesting enzyme to be used for the treatment of the following pollutants and wastes: aromatic amines, bromophenols, chloromethylphenols, methoxyphenols, chlorophenols, methylphenols, phenol, bleach plant effluent, cotton mill effluent and coal conversion wastewater (Aitken, 1993). Nowadays, great progress has been made using directed evolution inside $P$. pastoris. The enzyme showed a 2.3-fold higher specific activity towards the pollutant guaiacol and a 5.4-fold higher activity towards ABTS [2,2'-azinobis (3-ethylbenzthiazoline-6-sulfonic acid)]. ABTS is a chemical compound used to determine the enzyme kinetics or enzyme-linked immunosorbent assay. It is used as a substrate for horseradish peroxidase to identify its kinetics. Production of horseradish peroxidase was also realized in S. cerevisiae, but the enzyme from $P$. pastoris had a 5.6-fold higher total activity and a three-fold higher cell density (Morawski et al., 2000).

Acrylonitrile and acrylamide are widely used in petroleum industry and are the main pollutants in generated wastewaters. Their high toxicity and carcinogenicity are very dangerous, but nitrile hydratase showed bioconversion activity for these compounds. It was expressed in $P$. pastoris but, unfortunately, it was unstable and low activity was achieved. To solve this problem and enhance the activity of the enzyme, directed evolution can be used combined with another $P$. pastoris strain (Shi et al., 2004).

\section{Pulp bleaching and conversion of agrowaste}

In addition to manganese peroxidase, xylanase also provided excellent bleaching results. Moreover, xylanase is commercially important due to its ability to convert lignocellulosic material and agrowaste enabling the production of high value products such as furfural, xylitol, biofuels, and artificial low-calorie sweeteners. Xylanolytic en- zymes find their application in animal feed as they improve their digestibility by breaking down arabinoxylans and reduce the raw material viscosity. As it has already been stated, xylanase is also an effective enzyme for wood pulp bleaching and structure modification of pulp fibers (Barnoud et al., 1986). Together with manganese, peroxidase increased pulp delignification $(\mathrm{Xu}$ et al., 2010). Xylanase treatment is important for baking, where it breaks down hemicelluloses in wheat flour and water insoluble hemicellulose is converted to soluble forms, leaving the dough softer and easier to knead. Fruit juices are also treated with xylanase to reduce their viscosity and improve organoleptic characteristics. Natural sources of xylanases are bacteria and fungi, while those from fungi have higher activity. On the other hand, fungi also secrete cellulase, which is undesirable for some industrial applications, especially during paper pulping and bleaching. Xylanases are produced using submerged or solid-state processes. Solid-state fermentation suffers due to some limitations such as lower process control or low capacity (Malhotra \& Chapadgaonkar, 2018). Since xylanase is a very interesting enzyme with wide use, its recombinant production has been studied. Xylanase was expressed in $P$. pastoris reaching very high yields $(1.2 \mathrm{~g} / \mathrm{L})$. The final yield of the enzyme is important for its further application in industry, which makes $P$. pastoris suitable for industrial production of high quantities of enzymes (Mellitzer et al., 2012). P. pastoris is not only suitable due to its high enzyme yields but also due to post-translation modifications like glycosylation enzyme which show better properties. Higher thermostability of glycosylated enzyme from $P$. pastoris compared to those from E. coli were confirmed (Fonseca-Maldonado et al., 2013). Recombinant xylanase was produced in $P$. pastoris by directed evolution which yielded a strain with 1,3-fold higher xylanase production compared with the parent strain (Ma et al., 2019). This result excellently demonstrates how directed evolution can improve the produced enzyme quality.

\section{Degradation of bioplastics waste}

The problem with plastic waste is probably the most widespread and well-known. That is why biodegradable plastics produced from renewable agricultural sources are a promising alternative. Polyhydroxyalkanoates have commercial potential as biodegradable thermoplastics; their biodegradation and mineralization are attributed to polyhydroxyalkanoate depolymerase from Thermobifida sp. The enzyme was expressed in $P$. pastoris and it catalyzed the degradation of poly-[(R)-3-hydroxy- 
butyrate] (PHB) films, which was accelerated in (R)-3-hydroxyvalerate copolymers with the maximum degradation rate of $882 \mathrm{ng} \cdot \mathrm{cm}^{-2} \cdot \mathrm{h}^{-1}$. Such prepared enzymes can be used in standard processing of bioplastics waste (Phithakrotchanakoon et al., 2009).

\section{Pichia recombinant products for alternative medical treatment}

Overuse of drugs is also an environmental problem because their residues are found in water or animals. It means that replacement of pathogens' control methods with e.g. enzymes or antigens has to be prioritized. Strains of $P$. pastoris were used to produce AHL-lactonase which can be used as a cure of Aeromonas hydrophila infection in fish. This serious pathogen causes hemorrhagic septicemia which is controlled by antibiotics and chemicals. Excessive use of chemicals for the treatment of this disease leads to their accumulation in the food chain and thus they can enter human body. In addition, frequent use of antibiotics results in "superbugs" (strains resistant to antibiotics). Recombinant production was successful and the results indicate the possibility of mass low-cost production of AHLlactonase (Chen et al., 2010). Another veterinary problem is caused by Boophilus microplus which is a cattle tick causing problems with their reproduction. Control methods of this ectoparasite include the use of chemicals which are costly and cause environmental and residual problems. Vaccination is a way of protection against tick infestations. Vaccine Gavac $^{\mathrm{TM}}$ (Heber Biotec S.A., Cuba), a recombinant $\mathrm{Bm} 86$ protein, is produced in $P$. pastoris and used in Latin America. Unlike other expression system (baculovirus, Aspergillus niger, E. coli) recombinant antigen expressed in $P$. pastoris is acquired in a highly immunogenic, glycosylated, and particulate form (Canales et al., 1997).

\section{Bioremediation of toxic compounds}

Cyanide is a very toxic and well-known compound. In plants such as almond, cassava, sorghum or flaxseed, cyanogenic products are widely distributed. Due to $\beta$-glucosidase in the intestines of mammals, acutely toxic hydrocyanic acid is produced and therefore detoxification is important for safe feeding of animals with these plants. Popular detoxification method is boiling, roasting, autoclaving, microwaving and extrusion. Also, $\beta$-glucosidase can be used to hydrolyze these compounds which releases hydrocyanic acid into air. This problem can be solved by cyanide hydratase which catalyzes the hydrolysis of cyanide to formamide. It is used for bioremediation of cyanide-containing wastes and to absorb hydrocyanic acid formed from the cyanogenic glycosides hydrolysis. Recombinant cyanide hydratase was produced in $P$. pastoris together with $\beta$-glucosidase to develop a novel co-enzymatic method with high degradation activity of cyanogenic glycosides. Enzyme preparation produced by recombinant $P$. pastoris completely decomposes cyanogenic glycosides and catalyzes the hydrolysis of more than $80 \%$ of cyanide (Wu et al., 2012).

$P$. pastoris recombinant proteins are not used only for pollutant degradation but also for their detection. One of the commercial $P$. pastoris product is Superior Stock produced by Nitrate Elimination Co. from Michigan (USA). It is a recombinant nitrate reductase used in kits to test nitrates in water, soil, and animal feed. Normally, nitrate is tested through its reduction to nitrite via a coppercadmium reagent, which is quite a toxic method (Campbell et al., 1997). Thus, an enzymatic analysis has been verified for accuracy, sensitivity and reliability showing minimum impact on people and providing reliable data (www.nitrate.com).

\section{Production on crude glycerol}

All mentioned enzymes were produced on purified glycerol in $P$. pastoris. However, there are many studies where crude glycerol was used for enzymes production, e.g. phytase, a very important industrial enzyme used as animal feed additive for swine, poultry, and fish (Xie et al., 2020). Production of recombinant phytase on crude glycerol was upscaled up to a 7.51 bioreactor. Enzyme activity and biomass concentration reached $137.8 \mathrm{U} / \mathrm{ml}$, and $146 \mathrm{~g} / \mathrm{L}$, respectively. Maximum specific growth rate was higher when using crude glycerol than glucose $\left(0.266 \mathrm{~h}^{-1}\right.$ vs. $\left.0.203 \mathrm{~h}^{-1}\right)$ as the carbon source; final enzyme activity obtained with glucose achieved 121.6 U/ml (Tang et al., 2009). This proves that crude glycerol does not negatively affect $P$. pastoris growth or recombinant protein expression, which is its advantage over other microorganisms.

\section{Conclusion}

High-level expression, growth to high cell densities and post-translation modifications prove that $P$. pastoris is a suitable microorganism for recombinant enzyme production. Given all available data of successfully produced enzymes, $P$. pastoris has also great potential in the environmental sector. Products of $P$. pastoris were able to degrade pesticides or replace them with more environmentally friendly variants, degrade phenol compounds, synthetic dyes, hydrocarbons, antibiotic residues, lignin, nitroaromatics, toluene, bioplastics, and toxic compounds like cyanide. Its products were used also for kraft pulp bleaching, detection of pollutants and as alternative medical treatment 
Tab. 2. Summary of enzymes produced by P. pastoris with positive effect on environment.

\begin{tabular}{|c|c|c|}
\hline Product & Environmental treatment & Reference \\
\hline Pexiganan & replacement of pesticides & Neshani et al., 2019 \\
\hline Organophosphorus hydrolase & $\begin{array}{l}\text { biodegradation of organophosphorus } \\
\text { pesticides }\end{array}$ & Shen et al., 2016 \\
\hline Kpkt & $\begin{array}{l}\beta-1,3 \text { glucanase and killer activity against } \\
\text { spoilage yeast in wine and sweet beverage } \\
\text { industry }\end{array}$ & Chessa et al., 2017 \\
\hline Laccase & $\begin{array}{l}\text { degradation of synthetic dyes, lignin, } \\
\text { nitrophenol, antibiotics and phenolic } \\
\text { pollutants }\end{array}$ & Zhou et al, 2018; Colao et al., 2006 \\
\hline Manganese peroxidase & $\begin{array}{l}\text { degradation of lignin, cellulose, hemi- } \\
\text { cellulose, polycyclic aromatic hydrocarbons, } \\
\text { chlorophenols, synthetic dyes, nitro- } \\
\text { aromatics, tetracyclines, oxytetracyclines, } \\
\text { bleaching of pulp }\end{array}$ & Xu et al., 2017; Xu et al., 2010 \\
\hline Lignin peroxidase & degradation of lignin & Wei \& Xianghua, 2009 \\
\hline Xylanase & $\begin{array}{l}\text { conversion of lignocellulosic material and } \\
\text { agrowaste to high-value products, paper } \\
\text { pulping and bleaching }\end{array}$ & Ma et al., 2019 \\
\hline Phytase & $\begin{array}{l}\text { helps to digest phytate which prevent } \\
\text { phosphorus pollution }\end{array}$ & Tang et al., 2009 \\
\hline Nitrate reductase & test nitrates in water & www.nitrate.com \\
\hline Cyanid hydratase & $\begin{array}{l}\text { detoxification of cyanogenic glycosides, } \\
\text { hydrolysis of cyanide }\end{array}$ & Wu et al., 2012 \\
\hline Horseradish peroxidase & $\begin{array}{l}\text { degradation of aromatic amines, phenolic } \\
\text { compounds, coal conversion wastewater, } \\
\text { bleach plant effluent }\end{array}$ & Morawski et al., 2000 \\
\hline Polyhydroxyalkanoat depolymerase & biodegradation of polyhydroxyalkonotes & Phithakrotchanakoon et al., 2009 \\
\hline Bm86 antigen & vaccine against Boophilus microplus & Canales et al., 1997 \\
\hline Keratinase & $\begin{array}{l}\text { improvement of nutrional value of feather } \\
\text { meal and alleviate the environmental } \\
\text { impact associated with its processing or } \\
\text { disposal }\end{array}$ & Porres at al., 2002 \\
\hline AHL-lactonase & control of Aeromonas Hydrophila & Chen et al., 2010 \\
\hline Nitril hydratase & conversion of acrylonitrile and acrylamide & Shi et al., 2004 \\
\hline Azoreductase* & degradation of azo dyes & so far not produced by $P$. pastoris \\
\hline Cyanidase* & treatment of cyanide & so far not produced by $P$. pastoris \\
\hline Lactoperoxidase* & degradation of chlorophenols & so far not produced by $P$. pastoris \\
\hline Polyphenol oxidase* & degradation of phenol compounds & so far not produced by $P$. pastoris \\
\hline
\end{tabular}

(Tab. 2). Due to many advantages of recombinant enzyme production, genetically engineered $P$. pas toris could completely replace the native sources of these enzymes. In addition, to enhance its positive environmental impact even more, combination of $P$. pastoris cultivation on crude glycerol, a biodiesel side product, with production of enzymes for environment treatment can be employed.

All these successful attempts point to the potential of $P$. pastoris production of other enzymes suitable for environmental treatment (Tab. $2 *$ ).

\section{Acknowledgement}

This work was supported by the Slovak Research and Development Agency under the Contract no. APVV18-0254. This publication is the result of the project implementation: Comenius University in Bratislava Science Park supported by the Research and Development Operational Programme funded by ERDF. Grant number: ITMS 26240220086. This publication was co-funded by project "ACCORD" (ITMS project code: 313021X329) supported by the Operational Programme Research and Development funded by ERDF. 


\section{References}

Ahn MY, Dec J, Kim JE, Bollag JM (2002) Journal of Environmental Quality 31(5): 1509-1515.

Aitken MD (1993) Chemical Engineering Journal 52: 49-58.

Aktar MW, Sengupta S, Chowdhury A (2009) Interdisciplinary toxicology 2(1): 1-12.

Alcade M, Ferrer M, Plou FJ, Ballesteros A (2006) Trends in Biotechnology 24(6): 281-287.

Ali N, Zhang Q, Liu Z-Y, Li F-L (2020) Applied Microbiology and Biotechnology 104 (5): 1-19.

Anastácio G, Santos K, Suarez P, Torres F, De Marco J, Parachin N (2014) Bioresource Technology 152: 505-510.

Barnoud F, Comtat J, Joseleau J, Mora F, Ruel K (1986) Biotechnology in the Pulp and Paper Industry: 69-73. Conference in Stockholm.

Bartocci P, Bidini G, Asdrubai F, Beatrice C, Frusteri F, Fantozzi F (2018) Renewable Energy 124: 172-179.

Bassil KL, Sanborn VM, Cole DC, Kraur JS, Kerr KJ (2007) Canadian Family Physician 10(53): 1704-1711.

Campbell ER, Corrigan JS, Campbell WH (1997) Field determination of nitrate using nitrate reductase: 851-860. Conference in Pittsburg.

Canales M, Enríquez A, Ramos E, Cabrera D, Dandie H, Soto A, ... de la Fuente R (1997) Vaccine 15(4): 414-422.

Cereghino JL, Cregg JM (2000) FEMS Microbiology Reviews 24: 45-66.

Colao MC, Lupino S, Garzillo AM, Buonocore V, Ruzzi M (2006) Microbial cell factories 5(31): 1-11.

Colao MC, Garzillo AM, Buonocore V, Schiesser A, Ruzzi M (2003) Appl Microbiol Biotechnol 63 (2): 153-158.

Cos O, Rámon R, Montesinos JL, Valero F (2006) Microbial Cell factories, 5(17).

Eibes G, Cajthaml T, Moreira MT, Feijoo G, Lema JM (2006) Chemosphere 64: 408-414.

Eton Bioscence (2003-2019). Standard peptide synthesis. Retrieved from www.entobio.com.

Farnoosh G, Latifi AM (2014) Journal of Applied Biotechnology Reports 1(1): 1-10.

Fischer JE, Glieder A (2019) Current Opinion in Biotechnology 59: 175-181.

Fonseca-Maldonado R, Vieira DS, Alponti JS, Bonneil E, Thibault P, Ward RJ (2013) Journal of biological chemistry 288: 25522-25534.

Gaitan IJ, Medina SC, González JC, Rodríguez A, Espejo ÁJ, Osma JF, ... Sánchez OF (2011) Bioresource Technology 102: 3632-3635.

Hammel KE, Jensen KA, Mozuch MD, Landucci LL, Tien M, Pease A (1993) The Journal of biological chemistry 268(17): 12274-12281.

Chen R, Zhou Z, Cao Y, Bai Y, Yoa B (2010) Microbial Cell Factories 9(39).

Chessa R, Landolfo S, Ciani M, Budroni M, Zara S, Ustun M, ... Mannazzu I (2017) Appl Microbiol Biotechnol 101(7): 2931-2942.

Lazarev VN, Govorun VM (2010) Applied Biochemistry and Microbiology 46: 803-814.

Levil L, Carabajal M, Hofrichter M, Ulrich R (2016) Int Biodeter Biodegr 107: 174-179.

Li T, Takkellapati S (2018) Biofuels, Bioproducts and Biorefining 12(5): 756-787.
Ma C, Tan ZL, Lin Y, Han S, Xing X, Zhang C (2019) Journal of Bioscience and Bioengineering 6(128): 662-668.

Macauley-Patrick S, Fazenda ML, McNeil B, Harvey LM (2005) Yeast 22: 249-270.

Mahmood I, Imadi SR, Shazadi K, Gul A, Hakeem KR (2016) Plant, Soil and Microbes: 253-269.

Malhotra G, Chapadgaonkar SS (2018) BioTechnologia, Journal of Biotechnology, Computational Biology and Bionanotechnology 99(1): 59-72.

Markošová K, Weignerová L, Rosenbegr M, Křen V, Rebroš M (2015) Frontiers in Microbiology 6(1140).

McCauley LA, Anger WK, Keifer M, Langley R, Robson MG, Rohlman D (2006) Environmental Health Perspectives 114(6): 953-960.

Mellitzer A, Weis R, Glieder A, Flicker K (2012) Microbial Cell Factories 11(61).

Morawski B, Lin Z, Cirino P, Joo H, Bandara G, Arnold FH (2000) Protein Engineering 13(5): 377-384.

Moreira MT, Feijoo G, Lema JM (2003) Reviews in environmental science and Bio Technology 2: 247-259.

Mulchandani A, Mulchandani P, Kaneva I, Chen W (1998) Analytical chemistry 70(19): 4140-4145.

Neshani A, Tanhaeian A, Zare H, Eidgahi RM, Ghazvini K (2019) Gene Reports 17.

Nigam P, Armour G, Banat I, Singh D, Marchant R (2000) Bioresource Technology 72: 219-226.

Owens JW, Swanson SM, Birkholz DA (1994) Chemosphere 29(1): 89-109.

Paszczyński A, Huynh V-B, Crawford R (1985) FEMS Microbiology Letters 29(1-2): 37-41.

Phithakrotchanakoon C, Daduang R, Thamchaipenet A, Wangkam T, Champreda V (2009) Appl Microbiol Biotechnol 82(131): 131-140.

Ramsay JA, Nguyen T (2002) Biotechnology Letters 24: $1757-1761$.

Satyanarayana T, Kunze G (2009) Yeast Biotechnology: Diversity and Applications. Springer, Dordrecht.

Sheldon RA, van Rantwijk F (2004) Australian Journal of Chemistry 57: 281-289.

Shen W, Ma L, Shu M, Ni H, Yan H (2016) Protein expression and purification 119: 110-116.

Shi Y, Yu H, Sun X, Tian Z, Shen Z (2004) Enzyme and microbial technology 35: 557-562.

Shimazu M, Mulchandani A, Chen W (2001) Biotechnology and Bioengineering 4(76): 318-324.

Shraddha Shekher R, Sehgal S, Kamthania M, Kumar A (2011) Enzyme Research 2011: 1-11.

Scheibner K, Hofrichter M (1998) J. Basic Microbiol. 38(1): 51-59.

Schutter KD, Lin Y-C, Tiels P, Hecke AV, Glinka S, Weber-Lehmann J, ... Callewaert N (2009) Nature Biotechnology (27): 561-566.

Songa EA, Okonkwo JO (2016) Talanta (155): 289-304.

Sun B, Wibowo D, Middelberg AP, Zhao C-X (2018) AMB Express 8(6).

Syn High Quality Peptide (2010-2015). Peptide synthesis price list. www.synpeptide.com.

Tanaka K, Padermpole K, Hisanaga T (2000) Water research 1(34): 327-333.

Tang S, Boehme L, Lam H, Zhang Z (2009) Biochemical Engineering Journal 43: 157-162. 
Viikari L, Ranua M, Kantelinen A, Sundquist J, Linko M (1968) Bleaching with enzymes: 67-69 Conference in Stockholm.

Wei W, Xianghua W (2009) Journal of environmental science 21, 218-222.

Wen X, Jia Y, Li J (2010) Journal of Hazardous Materials 177, 924-928.

Wu C-F, Feng A-J, Xu X-M, Huang S-H, Deng M-C, Zheng X-N, ... Wang J-H (2012) African Journal of Biotechnology 11(19): 4424-4433.
Xie Z, Fong W-P, Tsang PW-K (2020) Enzyme and microbial technology 137.

Xu H, Guo M-Y, Gao Z-H, Bai X-H, Zhou X-W (2017) BMC Biotechnology 17(19): 1-12.

Xu H, Scott GM, Jiang F, Kelly C (2010) Holzforschung 64(2): 137-143.

Yehia RS (2014) Brazilian Journal of Microbiology 45(1): 127-133.

Zhou R, Yu H, Yuan P, Fan J, Chen L, Li Y, ... Zhang X (2018) Journal of Hazardous Materials 344: 499-510. 